\title{
UNIVERSITY oflfork
}

This is a repository copy of Bugs in the Blog: : immunitary moralism in Anti-Microbial Resistance (AMR).

White Rose Research Online URL for this paper:

https://eprints.whiterose.ac.uk/119667/

Version: Accepted Version

\section{Article:}

Brown, Nicholas Gerard Francis orcid.org/0000-0002-4742-8595 and Nettleton, Sarah Joan orcid.org/0000-0002-5184-2764 (2017) Bugs in the Blog: : immunitary moralism in Anti-Microbial Resistance (AMR). Social Theory and Health. pp. 1-21. ISSN 1477-8211

https://doi.org/10.1057/s41285-017-0030-9

\section{Reuse}

Items deposited in White Rose Research Online are protected by copyright, with all rights reserved unless indicated otherwise. They may be downloaded and/or printed for private study, or other acts as permitted by national copyright laws. The publisher or other rights holders may allow further reproduction and re-use of the full text version. This is indicated by the licence information on the White Rose Research Online record for the item.

\section{Takedown}

If you consider content in White Rose Research Online to be in breach of UK law, please notify us by emailing eprints@whiterose.ac.uk including the URL of the record and the reason for the withdrawal request. 
Bugs in the Blog: immunitary moralism in Anti-Microbial

\section{Resistance (AMR)}

Social Theory and Health (accepted 2017)

Nik Brown and Sarah Nettleton

Department of Sociology

University of York, UK

Corresponding author:

Professor Nik Brown (nik.brown@york.ac.uk)

Science and Technology Studies Unit (SATSU)

Department of Sociology

University of York

Y010 5DD

07968970498 
Bugs in the Blog: immunitary moralism in Anti-Microbial Resistance (AMR)

\section{Abstract}

This paper examines social theoretical literatures on immunity in the context of contemporary biopolitical debates about antibiotics and antimicrobial resistance (AMR). An exploration of contributions to the online forum 'Mumsnet' about antibiotic use and AMR serves as an empirical anchorage to these literatures. Five themes emerge from these data: 'temporal constraints and technological fixes'; 'restorative bodies'; 'spatial othering'; 'moral accountabilities' and 'domestic immunitary environments'. We offer the concept 'immunitary moralism' to capture the way antibiotics prompt moral reflection on immunity, biopolitical citizenship, bodily integrity and communal probity. We reveal how the moral politics of blame and immunitary othering are present in online debates about AMR, and explore the way these registers resonate with writings in biopolitical philosophy on the ascendency of immunitary individualism and tensions between community and immunity (communitas and immunitas).

Keywords: antibiotic resistance (AMR), othering, biopolitics, community, immunity 


\section{BUGS IN THE BLOG: IMMUNITARY MORALISM IN ANTI-MICROBIAL}

\section{RESISTANCE (AMR)}

\section{INTRODUCTION}

Since the early 1990s health policy internationally has become increasingly preoccupied with resistant infections, the future of antibiotic efficacy and the legacy of their 'overuse'. Various reports presage a future 'post-antibiotic apocalypse' of global 'epidemic' proportions (Brown and Nettleton 2016; Nerlich and James 2009; Newman et. al. 2015). In 2014, the former British Prime Minister, David Cameron foretold 'a return to the dark ages of medicine' identifying antibiotic resistance (AMR) as '... one of the greatest risks to modern medicine faced by this generation' (BBC 2014). The monetary economist, Jim O'Neil, was appointed by Cameron to oversee a review of AMR strategy (O'Neil 2016). For O'Neil the solution lies in substantial investment in pharmaceutical innovation, a 'global awareness campaign' and changes in prescribing behaviour. He also acknowledges that there is limited understanding of the varied sociocultural contexts in which antibiotics and infections are located. Indeed, as a previous UK government report highlighted, there is the need for more 'qualitative work' into the views and practices through which resistance has evolved (House of Commons 2014: 9).

Our paper responds directly to this call, by exploring the dominant discourses through which antibiotics, immunity and resistance are debated in Mumsnet.com, a prominent online forum and key site in the exchange of 
healthcare advice (Hine 2014; Skea et. al. 2008). We examine the way antibiotics prompt moral reflection on immunity, the immune system, and both the avoidability and unavoidability of common infections. Throughout the paper we suggest that infections and antibiotics serve as incendiary points of mutual scrutiny and criticism amongst online participants. These discussions exhibit contending discourses of communal and individual bodily probity, or ‘biopolitical citizenship’ (Rose 2007).

We locate our work in recent theoretical reflections on immunity. 'Immunitary theory' offers analytic insight into the tensions manifest in competing discourses played out in discussions about antibiotics and infections. We draw on the writings of scholars such as Emily Martin, Alfred Tauber, Ed Cohen, Jacques Derrida and Roberto Esposito. Each have written of the way transformations in immunological discourse relate to changing conceptions of self, security, protection and community. Discourses of immunity and resistance, they argue, bring into focus a series of frictions that we suggest have intensified in debates about the future of antibiotics, and indeed the 'post-antibiotic apocalypse.' We will begin by outlining some aspects of the work of these thinkers before turning to our empirical Mumsnet data. The online exchanges of the site provide a window onto a variety of cultural repertoires that circulate around antibiotics, resistance and immunity. The data therefore provide an apposite means to ground, and extend, social theorising on immunity.

\section{THEORISING IMMUNITY}


In Flexible Bodies, Martin (2014) historicises immunity documenting a move from immune systems conceptualised as defence mechanisms, to those conceptualised as agile and adaptable systems (see also Martin 1993). She describes how a flexibly adaptive immunitary discourse reproduces and resonates with the lexicon of post-Fordist economies, of personal enterprise, resilience and immunitary investment. The privileging of 'flexibility' is bound up, she writes, with the 'emergence of the immune system, one of our new taken-for granted virtues for persons and their bodies' (1994: xvii). Tauber (1995; 1995) also traces the ascendency of modern immunology documenting the demise of static conceptions of the self-versus-non-self (S/NS) system, and the emergence of immunological discourses underpinned by principles of adaptation and even learning. This is articulated through new disciplinary understandings related to, for example, autoimmunity, chimerism, transplantation, and parasitism. Each have ultimately eroded the static binary of the S/NS paradigm that dominated much mid-twentieth century immunology. For Tauber, such disciplinary transformations share intellectual terrain with developments in the computational and neurosciences. The immune system becomes reconfigured as an 'immune-nervous system' with the capacity to be 'over-written'.

What these authors trace then are discursive shifts within immunology and related disciplines. They articulate how these migrate into socio-political spaces and back again in to scientific discourse. Cohen's (2009) A body worth defending extends these debates further. He similarly writes of a shift towards discursive frameworks premised on immunitary preparedness, agility and the consequences of such immunitary imaginaries for social life: 
'[W] hat happens when we begin to reanimate ... immunity? Could we begin to recognize some of the imaginary work that metaphor performs in its bioscientific incarnations? And would this allow us to appreciate the transformations it brings to bear on the worlds in which we live? To address these questions, we might need to remember precisely what we forget when the metaphor 'immunity' functions as biomedical truth' (2009: 40)

The troubled connections between immunity and politics are further unpacked by Esposito (2008) writing of an 'immunity paradigm' in which the political and biological become inextricably intertwined. Indeed, talk about immunity and antibiotics, as we see below, bleeds equally into debates on public politics and personal responsibility. Immunity implies enclosure, protection and defence. And yet, to be effective rather than destructive immunity also requires a degree of openness, 'hospitable forms of immunity' that can 'preserve life' (Esposito, 2008: 53-54). Perhaps the most readily obvious example of this is vaccination, the introduction of a pathogen for individual and collective benefit.

Importantly for our discussion here, Esposito troubles the distinction between community and immunity (ibid.). He traces this tension to the etymological roots of immunity in the munus, the ancient and modern socio-legal structures of communal indebtedness, mutual obligation and gift. His argument is that a precarious balance has to be managed between protection and openness, retreat and contact, immunity and infectivity. Contagion, he writes, requires that we 
manage an unstable 'risky contiguity with the other' (2012: 49). The immunological self conceived in early twentieth century articulations presumed robust defences and isolation. The flexibly adaptive immunity characteristic of contemporary discourse is more porous and precarious. This precarity is 'felt as a risk to the individual identity of the subject precisely because it loosens, or breaks the boundaries that ensure the stability and substance of individual identity' (2012: 49).

But taken too far, our protections and defences can harbour dangerous autoimmunitary risks (Esposito 2011; Derrida 2003; Sloterdijk 2011). Disproportionately extreme immunitary designs, devices and defences are capable of recoiling dialectically in toxic self-violence. Protective designs can corrode collective or communal obligations and constitute a destructive relinquishment of mutual duty to others. The ascendency of the 'immunitary paradigm' is rife with difficult tensions between the affirmative and the damaging. Indeed, Esposito alludes to the way antibiotics are historically located in a hostile antagonistic relationship to microbial life (2012: 6). For Derrida (2003), the 'war on terror' illustrates the way protection gives rise to an autoimmune destructive response. Ultimately, our defences come to depend upon protection from protection. In other words, technologies designed to enable our protection, like antibiotics, frequently call upon us to critically evaluate our defences.

It is in these terms that immunitary social theory excavates an archaeology of immunological knowledge that straddles political philosophy and biology 
(Foucault 1970). It follows therefore that everyday talk about infections, antibiotics and resistance will resonate with these discursive tensions. We might also suggest that debates on the un/avoidability of infections and antibiotic use have the incendiary potential to be morally provocative. By this we mean AMR is permeated by a wider politics relating to notions of self, responsibility and community. Antibiotics as things - as actants - catalyse far-reaching ethical and moral contention cutting across the wider biopolitics of migration, nationhood, economy and citizenship (Brown and Nettleton 2016; Brown and Williams 2015).

In what follows therefore, we offer a sociological reflection on antibiotic debates in everyday virtual spaces. In particular, we examine how online participants critically evaluate the tensions between antibiotic consumption and abstinence. The empirical data, in the form of online discussions, are used here to facilitate further conceptual reflection in biopolitical theory on immunity. We therefore go beyond offering simply an insight into the 'views' of the 'public'. Instead, we want to think about the way AMR is framed as a problem of personal responsibility and the implications that follow.

This is timely as institutionalised responses settle on the need to generate public awareness, change behaviours, and develop diagnostic technologies or new antibiotics (O'Neill 2016). Immunitary theory encourages us to reflect on both dominant and alternative framings of AMR. The aim of this paper therefore is to explore 'lay expert' (Prior et. al. 2011) accounts in tandem with conceptual perspectives on immunitary biopolitics in order to decipher such possibilities. 
Before exploring these emergent themes in greater depth we offer some points of clarification on our empirical material.

\section{BUGS IN BLOGS - A BIOPOLITICAL RESEARCH SITE}

As an online social media environment, Mumsnet has been described as a 'mothering website' (Pedersen and Smithson 2013) for the exchange of information about a wide variety of topics, but with a particular concern for matters of health. It is visited by around $1.5 \mathrm{~m}$ users per month with roughly 30,000 posts made daily, becoming a significant platform for campaigning on healthcare, pornography, parenting, education and politics. The site has also proven to be productive terrain for research into pubescence (Roberts 2015), politics (Gambles 2010), sexualisation (Bragg and Buckingham 2013), and even parasitic headlice (Hine 2014). Pederson and Smithson (2013) found the site to be distinctive in '... its celebration of confrontational, opinionated and wellinformed debate ...' (2013: 97). Mumsnet has also been critiqued for reflecting the views of a 'profoundly narrow group of elite mothers: middle class, university educated and economically privileged' (Jensen 2013: 129). Whilst Mumsnet represents a very specific form of public with a contributing demographic of predominantly professional female parents aged in their mid 20 s to 40 s, it nevertheless offers a rich source of material for better understanding concerns central to this paper.

The ethical challenges of analysing data from online sources are complex (Markam and Buchanan 2012). As is often the case in social media research, whilst freely and publically available, Mumsnet contributors will not necessarily 
have anticipated that their posts would become research data. As with public printed matter, here notions of consent and the preservation of privacy are contentious. Nevertheless, the growing consensus in social media research is that consent is not normally required if the material is publically accessible without the need for a password or membership registration (Mann and Stewart 2000). We have however removed online participant 'names' and replaced them with ID numbers.

We identified 42 discrete threads on the site directly addressing antibiotic resistance contributed between 2007 and mid-2015. Each thread featured the terms 'antibiotics' and/or 'antibiotic resistance'. Our sample was confined to those threads directly addressing the topic rather than mentioning antibiotics in passing. We therefore exercised judgement in determining which threads to include in our corpus. These were then extracted into text documents for analysis and the identification of particularly distinctive or prominent contributions and exchanges. This resulted in a body of material comprising around 100,000 words subsequently probed for recurrent issues and salient tropes. These were coded inductively in relation to issues such as: views on antibiotic use, responsibility of prescribers and users, necessity for antibiotics, and overuse. We analysed the data while reflecting on theoretical debates on immunity, infection and resistance. Five themes emerged from this analysis: 'temporal constraints and technological fixes'; 'restorative bodies'; 'spatial othering'; 'moral accountabilities' and 'domestic immunitary environments'. These themes, perhaps unsurprisingly resonate with various metaphors and meanings of immunitary resistance. Participants, we find, often see antibiotics as 
a compromise and source of threat to the individual vitality and resilience of the immunitary self. But such compromises are often made within constraints not of participants' own choosing. Nevertheless, as we will see, they can also underpin what we refer to as 'immunitary moralism'.

\section{THE BIOPOLITICS OF ANTIMICROBIAL RESISTANCE}

Temporal constraints and technological fixes: 'When the axe is swinging at work'

Contributors to many of the threads frequently situate antibiotics in wider discussions about the unstoppable demands of parenting, work and other daily

obligations. More importantly, participants often see life's unrelenting flow to be a distinct feature of contemporary immunitary life, commonly resulting in the reluctant use of antibiotics. The emphasis placed on temporal flexibilisation, evident in expert and lay immunological discourse, is evident here (Martin 1994). Discussions of antibiotics and immunity fundamentally turn on temporal questions of timing, pace and frequency, exhibited through recurring tropes of the immune system and its embodied relationship to the dynamic demands of increasingly unpredictable living. Many contributors write of the impossibilities of arresting time, of slowing life down in order to recover from infection. Importantly, antibiotics are seen by contributors to replace or substitute for the availability of time. They write of the way antibiotics compress and truncate the temporalities of infectivity and symptoms. It is through such adaptive immunitary strategies that antibiotics make flexibilisation in employment and parenting possible. 
'I think part of the problem is that our work culture expects us to be able to go to the doctor, get a pill, and carry on doing our job whether that involves public facing services or using desks, phones, keyboards and being in close proximity to many coworkers' (ID2).

'... add to this mix the stress most people are feeling at work about their employment security and it's really very toxic. No one wants to be ill for extended periods when the axe is swinging at work' (ID12).

For many contributors, antibiotics are conceived as temporal technological devices, with which they can accomplish the task of projecting one's compromised or infected immunity back into the unstoppable flow of life. It is in these terms that antibiotics can be envisaged as prosthetic strategies that augment or supplement time and immunity simultaneously. As Martin (1994) suggests, contemporary immunitary life is characterised by an incitement towards flow, movement and contact with others rather than retreat and stasis. Immunity, for Martin has become indexed to the ascendance of a highly dynamic form of post-fordist 'flexibility'. Immunity is no longer static, passive or rigidly ordered. Instead, it is credited with agential inventiveness and innovation.

'I went to the GP today but they did prescribe antibiotics, but I got the lecture re antibiotic resistance and to allow it to settle first before cashing in the prescription... truth is, work is piling up and I have to go on a business trip, so I have got the prescription as I've found... that it usually gets a lot worse' (ID13) 
In many of these accounts, the archaic obduracy of the docile body is replaced by an iterative immunitary responsiveness. Malleable immunity requires an 'agile, anticipatory body, called into being in mutual association ... to a new wrinkle in the economic order, one that calls for perpetual innovation, flexible accumulation, frequent retraining, and geographical mobility on a global basis.' (Martin 1993: 71). In other words, the body is called upon to engage in reflexive bodily strategies, and to abandon those barriers preventing full immunitary agility, indexed to an erratic temporality (Tauber 1995).

\section{Restorative bodies: 'Sitting it out'}

Many of the threads contrast antibiotics against allowing an illness to 'run its course' or the idea that an infection should be 'endured'. Accepting temporary experiences of benign infection is also seen to require a degree of personal moral stoicism (Greenhough 2012). Lundgren (2015) recounts how the 'common cold' may be seen by some as a welcome opportunity for withdrawal into socially legitimate states of retreat from others and routine responsibilities involving social contact. In contrast to accounts cited in the previous section, infectiousness and its symptoms may become the occasion for voluntary intermission, an 'invitation' to interruption. Here, withdrawal is both a privilege and a moral obligation, an individual or private immunitas intended to serve the communitas (Esposito 2012).

Contributors are frequently critical of others' unwarranted expectations of 'instant' recovery, especially where this leads to premature antibiotic use. In 
many of these discussions, the ability to interrupt the flow of life in order to recover is seen to be a question of personal morality rather than the structural outcome of occupational, gendered or other circumstances. Davis et al. (2015) and Lundgren (2015) have written about this as 'choice immunity'; purposeful personal investment through which common infections can be overcome. 'Choice immunity' further implies that participants act as 'moral pioneers' (Rapp 1988) within shifting immunity landscapes. Not surprisingly the responses to discussions on Mumsnet reflect a complex mixture of both the highly individualised and the socially contingent.

'Expectations need to change as well. Sometimes you can't get instantly well ... I think people do expect to get instantly well. Which is why they take antibiotics for a virus rather than sitting it out.' (ID18)

The 'choice immunity' suggested here however reflects investment in one's own purposeful and volitional capacities. The deliberately chosen protracted event ('sitting out') arises from the freedom or opportunity to create personal immunitary intervals for recovery unaided by antibiotics. In other words, bodily vitality becomes a property of the individual through the creation of suspended temporal intervals. The following contrasts against those positions taken in the preceding section:

'Do they properly rest? I really think ours recover quickly if they completely rest. When 2 year old was ill last month we tried to spend most of the day in bed/ laying on sofa/sleeping/ fluids etc. Elder child (4) 
had admittedly boring day but was happy enough just playing with toys ... The next day he was almost back to normal. In comparison friends [... ] they are always ill for a week.' (ID1)

However, not all participants in these discussions go along with the argument that 'time heals'. Infectivity threatens the prolongation of symptoms, the possibility of suffering chronically recurring states of infection. Antibiotics are positioned in precariously ambivalent terms, as simultaneously sources of endangerment and necessity. As the extract above puts it, 'sitting it out' lies in sharp temporal contrast to the equally prevalent belief that 'the sooner you get on top of things the better'. Both of these positions articulate contrasting versions of an immunity that benefits from, or is vulnerable to, accelerated or decelerated cycles of infection and retreat.

'Sitting it out is all very well, but it doesn't help if your symptoms worsen and you are still turned away, and end up with a chronic long-term condition, as my sister has!' (ID15)

These competing conceptions of temporality resonate with shifts in immunology explored by Cohen (2009) and Tauber (1998) discussed above. These shifts express a conflict between the use of antibiotics to treat infection and defend against any further destruction, or on the other hand, to allow the agile creative body to restore its own immunological equilibrium. The 'swinging axe' and 'sitting it out' are particularly poignant metaphors for the precarity expressed in these opposing mandates of biomedical immunitary withdrawal, and bio- 
economic exchange (Esposito 2012). In such positions, the immunological self articulates highly contradictory logics that both drive them away from and encourage them to stay in contact with others, that identify their bodies as both the source and the negation of disease and fleshy decay' (Newman et. al. 2015: 19). While most public health advice advocates social distancing, lay accounts of immunity more usually stress the unavoidability of contact and the inevitability of common infections (cf Prior et al. 2011).

\section{Spatial othering: 'I had a particularly annoying au pair from france'}

Although temporally located, immunitary discourse is also spatially patterned and articulated. In many of these contributions, the immunitary threat of AMR takes on a regional and, in some instances, even a xenophobic inflection. For example, the 'off label' use of antibiotics (in which patients and practitioners deviate from prescription guidelines) are often attributed to 'foreign' (sic) rather than native practices. Likewise, the surplus availability of antibiotics 'lying around' is seen to come about through travel overseas or the transitory presence of foreign visitors. Moral designations of accountability frequently involve this regional and cultural 'othering' for the causes of resistance.

'I had a particularly annoying au pair from france who told me I ought to take DS2 to the doctor.... I said there was no point - it was a cold and he would be fine. She told me proudly that she had her own supply of antibiotics in her bedroom and she used them frequently. I told her that is was a bad idea' (ID6). 
This echoes similar lay representations of 'foreign' (sic) peoples, animals and places as sources of contagion responsible for novelty and virulence (Wald 2007). These spatial dimensions and temporal shifts are of course embedded within an increasingly global and interconnected traffic in bodies. Davis et. al. (2015) capture this neatly in their descriptions of an emergent immunocosmopolitanism' within which infection, vaccines and antibiotics are embedded in global flows and perturbations. Here, the threat of resistance is frequently presented as an incoming incursion from an alien without, or already within, the body and bodies of the nation. The prevention of AMR is widely viewed in these threads as largely ineffective in the face of this inevitable breaching of individual and national bodily borders. Many contributors also reproduce possibly alarmist discourses about foreign superbugs and encounters with unfamiliar symptoms and infections.

'This is not an anti-immigration thread... I believe that the UK is richer and better for its tolerance, openness, and diversity.... However, has anyone noticed that there are far more varieties of 'bugs' around in recent years? Not necessarily serious but just different. ... Symptoms just seem to be more varied.' (ID4)

'Even assuming that today's bugs came from foreign climates, how do you differentiate between foreign people bringing them here and the massive increase in British people travelling abroad and bringing them home?' (ID19) 
This cosmopolitan immunitary horizon or plane highlights the significance of what Esposito refers to as the 'spatiality of biopoliticised flesh' (2008: 160). Here blog contributors spatialise familiar and unfamiliar experiences of infectivity. Newman et. al. (2015) similarly reflect on the spatiality of infectivity and the way certain 'communal' or 'community' spaces, such as sports gymnasia, become sites of biopolitical technologisation. These are often spaces where particularly 'active' and fluid bodies are to be found: the bodies of children and athletes, bodies that they call 'viscoelastic'.

Many of the contributors to these threads write of places and events where the preservation of boundaries and withdrawal becomes impossible. Such 'pathogenic spaces' (Bewell, 2003) are locations riven with the paradoxical tensions between communal immersion and immunitary exemption. The former is governed by a logic of vitality that might include play, interaction, flow, exchange and productivity. The latter operates in relation to the barrier logic of individual securitisation including isolation, quarantine and stasis. The immunitary body is therefore always precariously suspended in these tensions between the fluid and static, between being in motion and arrested, and between communitas and immunitas.

'Spreading your germs around' in 'close proximity to co-workers' (see above) projects one into a particular spatiality of infective flesh. Mobile bodies leave immunitary versions of themselves on surfaces and on other bodies. How then is it possible for bodies to be biomedically framed as in need of containment or constraint, whilst also bio-economically uninterrupted? How is flow and 
uninterruptability preserved? As we discuss below, antibiotics sit ambivalently alongside hand sanitisers, household sterilising agents and other attempts to reconcile interaction with containment. Such 'bio-pedagogies' (Harwood 2009) might usefully be seen as everyday attempts to somehow preserve immunitas within the flow of communitas (Esposito 2012). Immunity is, we might say, temporarily borrowed through antibiotic strategies, thus facilitating spatial and temporal uninterruption.

\section{Moral accountabilities: 'Not many nowadays will do that'}

Many of the debates amongst these threads turn upon moral distributions of accountability and personal probity. It has been possible to see above how contributors apportion blame to a range of 'others' either irresponsibly using antibiotics or behaving carelessly in their immunitary etiquette. Infective incursion and antibiotic resistance are more usually attributed to 'external' factors and agents. Immunitary discourse is rife with conceptions of transmission originating externally and moving inward (Rosenberg 2002). That is, the 'within' or the 'inside' of immunitas is constantly threatened with violation from without. Lundgren (2015) after Martin (1993) both note how people tend to have confidence in their own immunitary values and practices, but roundly mistrust those of 'others'. This 'othering' of resistance chimes with what Blackman (2010) calls 'possessive individualism' (Blackman 2010), the sovereign immunitary subject of self-governance permeating biopolitics (Cohen 2009). 
Clearly, sources of threat are varied but frequently, in these threads, include older generations of patients and practitioners. 'Overuse' or inappropriate prescribing is conceived as the legacy of a passing generational population for whom antibiotics were ubiquitously available. In other words, resistance has become incorporated over evolutionary time within the contemporary biopolitics of immunity. Immunity inter-generationally accumulates hereditarily in the embodied memory of populations whose apparently liberal access to antibiotics collides with the present. In many of these accounts, older people are seen as vectors of threat to present-day parents and families. This echoes wider biopolitical anxieties about older people as sources of immunitary risk (Evans 2007). It is in comments about elderly patients and older practitioners that these discussions take on this distinctively trans-generational temporal inflection.

'An old lady I used to know told me proudly that her gp would write her a prescription for antibiotics if she just rang "and not many nowadays will do that"' (ID22)

'I had a mad old GP who didn't feel like she'd done anything unless she sent you out for a prescription for ABs. That was despite me knowing the illness was viral and her telling me it was viral.. ummm, why exactly ARE you giving me this prescription then?! Clearly she did it for the quiet life' (ID5)

In this way participants routinely draw explicit causal connections between the 'old days' of 'doling out a course straight away' and recent awareness of the risks 
of community resistance. What was once a source of immunitary protection for post-war patients is now seen to recoil back trans-generationally through new forms of risky exposure. We have seen above how the direction of immunitary threat travels from 'without' to 'within'. Here however, the biopolitics of accountability becomes a question of the past moving into the present.

And yet it is also important not to overstate the politics of blame in these accounts or to confuse blame with causation. Many participants sketched a picture of bygone populations blissfully unaware of the future harms for which they have since become accountable. Most of these discussions are circumspect in the attribution of intentional culpability to older populations. Like fossil fuels, antibiotics are generationally positioned as a scarce resource to be conserved, or indeed a spent resource responsible for environmental and ecological harm.

'So many were discovered so quickly, they seemed like an amazing miracle. And then we went crazy over-using them. Like oil and gas and stuff' (ID1A)

'Othering' also extends to those accused of placing unreasonable demands on practitioners, pressuring them to inappropriately 'give' antibiotics. Here the threat is seen to originate from wilful patients whose persuasion results in prescriptions given reluctantly by practitioners. Very few participants themselves acknowledge coaxing their clinicians into giving a prescription. Admitting directly asking for antibiotics rather than deferring to professional judgement is uncommon in these threads. Contributors often however recount 
being given prescriptions without explicitly requesting or anticipating them. This is possibly in agreement with at least some of the existing research on antibiotic prescribing. For instance, practitioners have been found to prescribe antibiotics if they believe, even mistakenly, that patients expect them (Butler et. al. 1998). More commonly, participants tend to use the threads to seek advice about whether their expectations are reasonable or not.

'They are terribly over-used but ... why??... My GP would not prescribe them for a minor condition and I wouldn't ask her for them. And even if I did ask, I wouldn't expect her to just give them to me because I'd asked nicely' (ID32)

'... user's son unwell for three weeks, the doctor said antibiotics won't make any difference. [I'm] asking for advice and whether being unreasonable to expect this medication... Too many people expect antibiotics for everything, too many doctors will give them' (ID18)

Participants in the threads who do acknowledge using pressure to procure a prescription tend to draw heated criticism. Similarly, the contributions below are less typical in illustrating the way the gatekeeper role of the prescriber is sometimes bypassed when an explicit request for antibiotics is declined. Where persuasion fails, the online market or the overseas market in antibiotics is occasionally seen to provide instead. Whilst drawing angry criticism online, a number of contributors seek advice from others about alternative routes to antibiotics or the safety of buying online. 
I buy them on the internet and abroad (and sometimes manage to persuade GP to prescribe just in case) I cannot afford to have time off work. I have on several occasions been fobbed off without antibiotics only to become very ill indeed, when I know antibiotics will cure it rapidly. (ID7)

More commonly however, participants who 'demand' antibiotics from practitioners, or illicitly procuring them online, are criticised as 'selfish'. These interrelated notions of selfishness and gifts are poignant reminders of the munus. The fact that prescriptions are 'given', or are 'in the gift' of the prescriber, is significant. The actions of social media contributors are open to the scrutiny of a virtual but also embodied community where 'inappropriate' antibiotic use is seen to deny communitas of the munus. At issue here is the obligation and debt to a wider collective, or the 'lack' within communitas as Esposito expresses it. To 'demand' or to 'expect' is to withhold one's reciprocal duty of accountable responsibility to the world in which one is biomedically and biopolitically located. At its extreme, in refusal of the munus, one excuses oneself through an exclusion or rejection of the needs of the community. Through refusal, the immunitary individual excludes and exiles the communitas.

As we discuss above, the munus is complex for Esposito and lies along a continuum between the benign and the burdensome. Immunitas, protection from communitas, is necessary yet simultaneously a source of community danger. Antibiotics are resonant of a 'terrible contradiction' as he puts it: 'what saves 
individual and collective life is also that which impedes its development, and indeed what, beyond a certain point, winds up destroying it' (Esposito 2012: 7). In AMR, the munus is the civic duty not to 'demand' that which is in the gift of communitas. In other words, the gift to be given is the duty of sacrificing one's claims to unlimited protection. The munus or duty expected is often presented as the toleration or 'communing' of subjects and pathogens rather than their strict separation. It is to this questions of 'co-immuning' that we now turn.

Domestic immunitary environments: 'How many of us use antibiotics in our homes just to keep them clean?'

For many contributors, immunitary health is compromised when antibiotics are seen to inhibit the nurturing of one's immunity. Responsible accountability for one's immunitary health and that of one's children depends not on exclusion but, rather, exposure to benign contagion. Many contributors document practices and views reflecting both the inevitability and also desire for communing with the microbial (Napier 2002; Greenhough 2012; Lohm et al., 2015).

The immune system is widely 'imagined' (Wald 2000) through these notions of tutelage or training, but without necessarily being anchored in a particular body of biomedical knowledge. Davis et. al. similarly write of a common variance between lay and biomedical accounts of immunity. Often, they write, the presumed benefits of contagion will draw upon a sense of 'bodily vitality that glosses over immunity's technical nuances' $(2015,14)$. Our findings here partly echo those of a recent Wellcome Trust study highlighting contrasting understandings of resistance between expert and non-expert immunological 
knowledge (Gray 2015). Contentiously, contributors frequently express the view that they themselves acquire resistance to antibiotics, rather than resistance being acquired by pathogens.

The idea that resistance is located in the human 'subject' rather than the pathogenic 'object' is, possibly, wholly consistent with immunitary individualism. Here immunity is something that must be 'primed' both developmentally through the lifecourse but also evolutionarily in the species. These discussions often express nostalgia for a past less preoccupied with sterility and healthier for it. Childhood, in particular, is often seen to have once been less domesticated than it is today, less opposed to some notional naturalness. Such 'nostalgia' is perhaps another form of 'immuno-cosmopolitanism', a longing 'for productive encounters with 'dirt' and traffic with foreign microbial life.' (Davis et. al. 2015, 20).

'Antibacterial cleaners and sterile environments are bad; you need your immune system to be primed, particularly through childhood. Our body is covered in bacteria, and we need them, most are harmless and outcompete other harmful microorganisms. [...] We need to get sick.' (ID26).

'It's all very well to blame the medics or blame the pharmacologists or even blame one's neighbours and friends. How many of use antibiotics in our homes just to keep them clean? Our immune systems are becoming less able to cope with the diversity of bacteria and viruses.' (ID13B) 
It is noteworthy in these discussions that antibiotics are often seen to share the same classificatory category as detergents. Many contributors to the threads are ambivalent about 'cleanliness' and see antibiotics extending household cleaning agents into the interior of the body itself. Some of these discussions are deeply preoccupied with the murky boundaries between antibiotics and other antibacterial products. It is here that various thresholds are called into question: between kitchen surfaces and the bloodstream; the exterior of the body and its interior; between exogenous and endogenous micro-fauna; and the ecologies of the home and the interior of the body.

'I would like to know more about cleaning products. I use anti-bacterial spray- does it really contain antibiotics? This leads me to wondering what the actual difference between an antibiotic and something that kills bacteria. Alcohol kills bacteria, so does salt, but they're not antibiotics. Is an antibiotic something that can enter the bloodstream?' (ID36)

Many of these contributions position antibiotics within the broader politics of cleanliness and sterility. Hinchliffe and Ward (2014), in their discussion of agricultural biosecurity, remind us of Esposito's subtle distinction between affirmative immunity and destructive exclusion. The exercise of immunity is not to be confused with the exclusion, banishment or prohibition of that which may add to life. Many of the discussions above reflect a biopolitics that is intensely sceptical of the possibility of immunitary exclusion. Rather, as may be now obvious, infection is often seen to be inevitable and even sometimes desirable. In 
Hinchliffe and Ward's case, this is illustrated in the way pig farmers talk of 'bugging-up' their herds, acclimatising livestock to new pathogens in unfamiliar surroundings. This echoes Esposito's point about immunity as a way of entering into a 'nonexcluding relation with the common opposite' (Esposito 2011, 17).

\section{CONCLUDING DISCUSSION: BUGS, BLOGS AND ANTIBIOTICS}

In this paper we add qualitative understanding to the way antibiotics are located culturally within various immunitary registers. We have therefore gone beyond a policy focus on behaviour, to reflect conceptually on online debates and in particular we have highlighted how these express biocitizenship and biotic prudence. We have seen how antibiotics are frequently recognised to be ineffective in the face of inevitably common infections. 'Coping without' antibiotics is typically articulated as a matter of bioethical reasoning and is critically contrasted against the medicinal behaviour of irresponsible 'others'. We capture these tensions through the notion of 'immunitary moralism' where decisions and practices relating to antibiotics resonate with notions of self, other, community and immunity. Immunitary moralism extends Davis et al's (2015) conception of 'choice immunity'. Here,one's immunitary constitution becomes a matter of purposeful biopolitical responsibility, highlighting how immunitary practices mesh with an ethics of self and collective care. Contributors in Mumsnet position antibiotics within the competing temporal and spatial dimensions of what Baylis et al refer to as 'relational solidarity' or 'relational personhood' and 'social justice' (2008: 205). 
By contrast, the recent O’Neil Report (2016) on AMR is articulated through a largely individualised rather than relational lens. This arguably atomistic approach envisages a world of misinformed patients and practitioners whose behaviour requires correction. As in other public health contexts (e.g. vaccination or obesity), the prism of 'behaviour' conceives of a biopolitical landscape populated by rationally calculative individuals. The purpose of intervention is thus to steer behaviours, to disseminate knowledge of riskiness, to re-articulate the dystopian threat of an impending personal or collective catastrophe. In this case, the politics of antimicrobial fear is articulated through the abstract prospect of 'a return to the dark ages of medicine' and the unravelling of modern medicine's achievements. Policies focussed on behaviour, we suggest, have the potential to intensify immunitary moralism with unintended, stigmatising, and socially divisive consequences.

It is worth pausing therefore, to think about the way this focus on fear and behaviour frames immunitary politics as in terms of rational selves pitted against a capricious world of reckless others. 'Individual behaviour' arguably isolates and segments its self-actualising agents (Rose 2007) from the unstoppable flow of immunitary life and organic living. Hobson-West suggests that the premium placed on rationally calculative behaviour reflects a discourse in which the '... social bonds of community are seen as less strong... [and where] concentrating on community benefits would be deemed unfashionable or unproductive' (Hobson-West 2003: 277). The rational-cerebral figure may be said to extract its subject from the embodied flux of co-immunities. 'Behaviour' separates the world into selves and others, the virtuous and the unruly, the 
safety of the within and the dangerousness of without. The discourse of behaviour therefore estranges and alienates the very selves to which it is directed. This represents a distinct tilt away from a potentially affirmative and porous civic immunitas, of immunitas for communitas and may be generative of spaces where immunitary moralism thrives.

Esposito locates this tendency historically in an auto-destructively sovereign individual preoccupied with the exclusionary fear of limitless others. His account suggests that many of our worst dangers are proportionate to our illusory confidence in having overcome them. 'There was,' he writes, 'a time in our societies in which fear, at least of the biological sort, was weakened... when the optimistic idea spread that antibiotics could rid the world of a number of millennial diseases' $(2012,6)$. For Derrida (2003) too, the source of autoimmunity is to be found in the catastrophism of immunitary imagination. It is therefore important to reflect critically on calculative individualism ('behaviour'), and the othering embedded within the discourse of immunitary catastrophism ('the return to the dark ages').

Lee and Motzkau (2012) similarly explore how the politics of climate change and AMR presumes a 'deliberate' sovereign subject. In reality however, both contexts reflect the entangled intensity of processes making it difficult to identify 'suitable moments of intervention'. Responses based on individual behaviour tend to 'have perverse outcomes' (2012: 450). They argue instead for alternative biosocial imaginations rooted in notions of 'emergence' that displace the anthropocentrism of volitional deliberate intent. Such immunitary 
entanglements are evident in the data discussed throughout this paper in accounts of parenting, work, wiping noses, of retreating to bed, of travel and encounters with others, etc. Debates about immunity and antibiotics found across the blogosphere are complex and often discordant. Many positions unsurprisingly reproduce the othering implied in dominant discourses of calculated behaviour. The threat of AMR is often seen to originate from without (from elderly generations, foreign au-pairs, self-interested patients, and browbeaten practitioners spoiling patients like indulged infants). Othering locates resistance in those whose belonging within communitas is called into question. These modes of immunitary distancing reflect and imitate processes of othering encoded in discourses of individual biopolitical self-prudence.

But throughout these debates we also discern a competing biopolitics that offers a different slant on immunitary moralism. This may include an affirmative immunity, articulated through biotic exposure, immunitary porosity and the relaxation of our chemotherapeutic defences. They can be discerned in a critical regard for iatrogenic antibiotics, detergents and the pharmacological excesses of sterility. The body and the home are also potentially reconfigured as contexts of 'rewilding' (Lorimer 2014) and engagement with 'good' biotic life. What constitutes 'good' is invariably contingent and far from clear-cut. 'We need them', as one contributor puts it, suggests the de-domestication of the biotic and ourselves. In this vein Paxson (2008) writes of a 'post-pasteurian' immunity where hygiene is not necessarily abandoned but instead taken more seriously requiring more discrimination (Paxson 2013). 
The post-pasteurian figure is one rooted in a sense of the body ubiquitously colonised by the microbial in a cohabitation evolutionarily rooted in interspeciesness. Helmreich expresses this as 'homo microbis', a 'symbiopolitics' (2011) in which subjects selectively transgress biotic othering. Here, the antibiotic 'age' becomes an irregular ripple in that ecological co-evolution. The lasting effects of that ripple extend from the past into uncertain future immunitary openings. It would, however, also be naïve to mistake this for a return to the wildness of the pre-antibiotic, or an unproblematic opening into the post-antibiotic.

\section{References}

Baylis, F., Kenny, N. P., \& Sherwin, S. (2008) A relational account of public health ethics. Public Health Ethics, 1, 3, 196-209

Bewell, A. (2003) Romanticism and colonial disease. JHU Press

BBC (2014) Antibiotic resistance: Cameron warns of medical 'dark ages', 2nd July, http://www.bbc.co.uk/news/health-28098838 [accessed 1/7/16] Blackman L (2010) Bodily integrity. Body \& Society, 16, 1-9

Bragg, S., \& Buckingham, D. (2013) Global concerns, local negotiations and moral selves: Contemporary parenting and the "sexualisation of childhood" debate. Feminist Media Studies, 13, 4, 643-659

Bragg, S., \& Buckingham, D. (2013) Global concerns, local negotiations and moral selves: Contemporary parenting and the "sexualisation of childhood" debate. Feminist Media Studies, 13, 4, 643-659 
Brown, N. \& Nettleton, S. (2016) 'There is worse to come': the biopolitics of traumatism in Antimicrobial Resistance (AMR). The Sociological Review, DOI: $10.1111 / 1467-954 X .12446$

Brown, N., \& Williams, R. (2015). Cord blood banking-bio-objects on the borderlands between community and immunity. Life sciences, society and policy, 11,1, 1-18

Butler, C. C., Rollnick, S., Pill, R., Maggs-Rapport, F., \& Stott, N. (1998) Understanding the culture of prescribing. British Medical Journal, 317, $7159,637-642$

Cohen, E. (2004) My self as an other: on autoimmunity and "other" paradoxes. Medical Humanities, 30,1, 7-11

Cohen, E. (2009). A body worth defending: Immunity, biopolitics, and the apotheosis of the modern body. Duke University Press.

Davis, M., Flowers, P., Lohm, D., Waller, E., \& Stephenson, N. (2015) Immunity, Biopolitics and Pandemics Public and Individual Responses to the Threat to Life. Body \& Society, $1357034 X 14556155$.

Derrida, J. (2003) Autoimmunity: Real and symbolic suicides, In G. Borradori [Ed.] Philosophy in a Time of Terror, Chicago: University of Chicago Press. Esposito, R. (1995) Donner la technique. La Revue du MAUSS, 2, 6, 190-206. Esposito, R. (2008) Bios: biopolitics and philosophy. Minneapolis: University of Minnesota Press.

Esposito, R. (2011) Immunitas: The Protection and Negation of Life, Malden, MA: Polity.

Esposito, R. (2012) Terms of the Political: Community, Immunity, Biopolitics, New York: Fordham University Press 
Esposito, R. (2012). Immunization and violence.

http://www.biopolitica.org/docs/Esposito_Immunization_Violence.pdf (accessed 1/6/2016)

Evans, M.R, et al. (2007) A qualitative study of lay beliefs about influenza immunisation in older people. British Journal of General Practice 57:352358.

Foucault, M. (1970) The Order of Things: Archaeology of the Human Sciences London: Tavistock

Gambles, R. (2010) Going public? Articulations of the personal and political on Mumsnet. com. Innovations in Research, Theory and Politics, 29-42.

Gray, K. A. (2015) Antimicrobial resistance: still widely misunderstood, The Wellcome Trust, https://blog.wellcome.ac.uk/2015/07/29/antimicrobialresistance-still-widely-misunderstood/ (accessed 1/6/2016)

Greenhough, B. (2012) Where species meet and mingle. Cultural Geographies, 1474474011422029.

Harwood, V. (2009) Theorizing biopedagogies. Biopolitics and the "obesity epidemic", Governing Bodies, 15-30.

Helmreich, S. (2011) Homo microbis and the Figure of the Literal. Cultural Anthropology Online, April, 24.

Hinchliffe, S., \& Ward, K. J. (2014) Geographies of folded life: How immunity reframes biosecurity. Geoforum, 53, 136-144.

Hine, C. (2014) Headlice eradication as everyday engagement with science: An analysis of online parenting discussions. Public Understanding of Science, $23,5,574-591$. 
Hobson-West, P. (2003) Understanding vaccination resistance: moving beyond risk. Health, Risk \& Society, 5, 3, 273-283

House of Commons (2014) Ensuring access to working antimicrobials, London: The Stationary Office

Jenson, T. (2013) 'Mumsnetiquette': Online Affect within Parenting Culture. In C. Maxwell and P. Aggleton (Eds) Privilege, Agency and Affect: Understanding the Production and Effects of Action, 127-145

Lee N. and Motzkau J (2012) Varieties of Biosocial Imagination: Reframing Responses to Climate Change and Antibiotic Resistance, Science, Technology, \& Human Values 38, 4, 447-469

Lohm, D., Davis, M., Flowers, P. \& Stephenson, N. (2015) 'Fuzzy' virus: indeterminate influenza biology, diagnosis and surveillance in the risk ontologies of the general public in time of pandemics. Health, Risk \& Society, $17,2,115-131$.

Lorimer, J., \& Driessen, C. (2013) Bovine biopolitics and the promise of monsters in the rewilding of Heck cattle. Geoforum, 48, 249-259.

Lundgren, B. (2015) The Common Cold, Influenza, and Immunity in PostPandemic Times, Health, Culture and Society, 8, 2, 46

Mann, C. and Stewart, F. (2000) Internet Communication and Qualitative Research. A Handbook for Researching Online. London. Sage Publication Markam, A. and Buchanan, E. (2012) Ethical Decision-Making and Internet Research: Recommendations from the AoIR Ethics Working Committee (Version 2.0) Association of Internet Researcher (AoIR) http://aoir.org/ethics/ 
Martin, E. (1993) Histories of immune systems. Culture, Medicine and Psychiatry, $17,1,67-76$

Martin, E. (1994) Flexible bodies: Tracking immunity in American culture from the days of polio to the age of AIDS. Beacon Press.

Napier, A.D. (2002) The age of immunology. Conceiving a future in an alienating world. University of Chicago Press.

Nerlich, B., \& James, R. (2009). "The post-antibiotic apocalypse" and the "war on superbugs", Public Understanding of Science, 18, 5, 574-590.

Newman, J. I., Shields, R., \& McLeod, C. M. (2015) The MRSA Epidemic and/as Fluid Biopolitics. Body \& Society, 1357034X14551844.

O’Neil, J. (2016) Tackling Drug-Resistant Infections Globally: final report and recommendations, Wellcome Trust and HM Govt http://amrreview.org/sites/default/files/160525_Final\%20paper_with\%20cover.pdf [accessed 1/7/16]

Paxson, H. (2008) Post-Pasteurian cultures, Cultural Anthropology, 23, 1, 15-47

Paxson, H. (2013) on Post-Pasteurianism, http://blog.castac.org/2013/08/heather-paxson-winner-of-the-2013forsythe-prize-on-post-pasteurianism/ [accessed 1/7/16]

Pedersen, S., \& Smithson, J. (2013,). Mothers with attitude-How the Mumsnet parenting forum offers space for new forms of femininity to emerge online. Women's Studies International Forum, 38, 97-106

Prior, L., Evans, M. R., \& Prout, H. (2011) Talking about colds and flu, Social Science \& Medicine, 73, 6, 922-928

Roberts, C. (2015) Puberty in crisis: the sociology of early sexual development. Cambridge University Press. 
Rose, N. (2007). Molecular biopolitics, somatic ethics and the spirit of biocapital. Social Theory \& Health, 5, 1, 3-29

Rosenberg, C.E. (2002) The Tyranny of Diagnosis, The Milbank Quarterly, 80, 2, $237-260$

Skea, Z. C., Entwistle, V. A., Watt, I., \& Russell, E. (2008) 'Avoiding harm to others' considerations in relation to parental measles, mumps and rubella (MMR) vaccination discussions, Social Science \& Medicine, 67,9, 1382-1390

Sloterdijk P. (2011) Spheres, vol. 1: Microspherology, New York: Semiotext(e)

Tauber, A. I. (1995) Postmodernism and immune selfhood. Science in Context, 8, 4, 579-608

Tauber, A. I. (1998) Conceptual shifts in immunology: Comments on the 'twoway paradigm'. Theoretical Medicine and Bioethics, 19, 5, 457-473

Wald, P. (2000) Imagined Immunities. Cultural Studies and Political Theory, 189208

Wald, P. (2007) Contagious: cultures, carriers, and the outbreak narrative. Duke University Press 